\title{
NARRATIVAS E DESENHOS (IMAGENS) NO ENSINO FUNDAMENTAL COM TEMAS GEOCIENTÍFICOS
}

\section{Narratives and drawings (images) with Geosciences themes in primary and secondary schools}

\author{
Maurício Compiani ${ }^{1}$
}

Resumo: $\mathrm{O}$ artigo discute narrativas e desenhos no ensino de temas geocientíficos nos resultados de dois projetos de formação continuada no Ensino Fundamental. O foco é nas atividades desenvolvidas por professoras de Português, Geografia e Artes que trabalharam interessantes articulações entre observação-leitura, com elaboração de textos/narrativas, descrições/narrativas, representações visuais e visoverbais (desenhos) de objetos ou eventos geocientíficos. O modo histórico de explicação do mundo pela Geologia/Geociências abre um leque de práticas de ensino-aprendizagem pouco usuais no Ensino Fundamental. Práticas que constituem as explicações escolares geocientíficas, lidando com a imagem, a percepção e a síntese nas suas inter-relações em como os objetos e espaços são significados e construídos conjugadamente com os raciocínios de causalidade e as narrativas históricas. Uma das ideias é mostrar que, na elaboração de conceitos mais generalizantes e histórico-espaciais, os processos de construção de conhecimentos são contínuos e descontínuos entre contextualização e descontextualização, síntese e análise.

Palavras-chave: Ensino Fundamental. Ensino de geociências. Linguagem visual. Narrativa geocientífica.

Abstract: This article discusses narratives and drawings with geosciences themes within teaching at the conclusion of two in-service teaching projects in the primary and secondary school. The spotlight is in the developing activities by teachers of Portuguese, Geography and Art. These teachers developed interesting connections between reading and observation by building narrative texts, narrative descriptions, visual and visual-verbal representations (drawings) of objects of geosciences events. The historical explanations in Geology/Geosciences open a range of learning and teaching practices, which have been hardly ever been used in primary and secondary school. These practices which compose geosciences school explanations deal with images, perception and synthesis in their relationships between objects and spaces. This reasoning has been built and defined connected to casual reason and historical narratives, it becomes a more generalized concept in the special and historical context. In this case, the processes of knowledge construction are continuous and discontinuous among contextualization, decontextualization, synthesis and analysis.

Keywords: Primary and secondary school. Geosciences teaching. Visual language. Geosciences narrative.

\footnotetext{
${ }^{1}$ Universidade Estadual de Campinas (Unicamp), Instituto de Geociências, Caixa Postal 6152, CEP 13083-970, Campinas, SP, Brasil. Email: compiani@ige.unicamp.br
} 


\section{Introdução}

Este artigo discute relações entre a linguagem verbal e visual, especificamente o uso de narrativas, desenhos e imagens com temas geocientíficos na escola básica. Os dados são de dois projetos: o primeiro, intitulado 'Geociências e a formação continuada de professores em exercício do Ensino Fundamental'2, desenvolvido de 1997 a 200133; o segundo, chamado 'Conhecimentos escolares relacionados à ciência, à sociedade e ao ambiente em microbacia urbana ${ }^{4}$, desenvolvido de 2007 a $2010^{5}$. A temática da Geologia/Geociências foi trabalhada em salas de aula, na época, com alunos da $5^{a}$ a $8^{a}$ séries (11 a 14 anos) da escola pública. Em ambos os projetos, o grupo de pesquisa era multidisciplinar: no primeiro projeto, era composto por professoras de Ciências, Geografia e Português; no segundo projeto, por professoras de Artes, Geografia, Português e Matemática.

Vou colocar o foco nas atividades de ensino-aprendizagem desenvolvidas que trabalharam interessantes articulações entre observação-leitura-interpretação, com elaboração de textos/narrativas, descrições/narrativas, desenhos/narrativas e desenhos/escrita de objetos ou eventos geocientíficos. Em todas essas atividades, o papel das práticas de campo e estudos do lugar/ambiente foi fundamental. Os trabalhos de campo são um dos resultados metodológicos mais importantes dos projetos. Ele foi um dos recursos mais poderosos para contextualizar o ensino, levando em conta o entorno da escola de modo amplo, socioambientalmente.

A Geologia/Geociências pode contribuir para uma concepção mais elaborada de mundo, sendo, como Paschoale (1984) já apontou, um conhecimento fundamental para a alfabetização da e na natureza. A Geologia/Geociências pode propiciar cognições básicas que alicercem as elaborações conceituais dos alunos, pois implicam e ampliam noções de espaço e tempo, dos condicionantes do contexto (amplos do ambiente e da sociedade, de escalas do lugar até o mundo global) para as relações de causalidades; ampliam o papel destacado da imagem e suas relações com a percepção e síntese, como, também, do argumentar e narrar histórico e de uma visão de natureza menos antropocêntrica. Cognições cujas aquisições implicam novos modos de ver, ler e explicar o mundo, novos procedimentos e novas organizações conceituais.

Trabalhar com Geologia/Geociências é excitante do ponto de vista teórico-prático pois abre um leque de opções de trabalho com aspectos quase sempre deixados de lado ou pouco enfocados no Ensino Fundamental. Penso que o tema deste trabalho nos dá condições de apenas iniciar a ideia de entender o papel da imagem, da percepção e da síntese nas suas inter-relações em como os objetos (formas) e espaços (contextos) são significados e construídos, constituindo padrões espaço-temporais que podem ser transformados em estruturas de suporte lógico (scaffolding) discutido por Bruner e Haste (1990), como, também, nas suas interrelações com os raciocínios de causalidade e as narrativas históricas. Acredito que esses aspec-

\footnotetext{
${ }^{2}$ Projeto financiado pela FINEP: 63.96.0785.00, pelo CNPq: 524360/96-0 e pela FAPESP: 96/2566-4.

${ }^{3}$ Para mais detalhes, ver Compiani $(1999,2002)$ e Compiani et al. (2000).

${ }^{4}$ Projeto financiado pela FAPESP: 06/1558-1, pelo CNPq: 309353/09-2 e pelo Programa Petrobras Ambiental.

${ }^{5}$ Para mais detalhes, ver Compiani et al. (2010) e <http://ead.ige.unicamp.br/anhumas/>. 
tos pouco tratados no Ensino Fundamental são importantes na formação das crianças porque podem desenvolver: a capacidade de abstração, o pensamento histórico, o raciocínio espacial e a perspectiva mais relacional e complexa.

Há uma questão que já comecei a discutir em outro trabalho (COMPIANI, 1998) e à qual, de alguma forma, retorno e amplio neste, que é a de se pensar a narrativa não apenas como um gênero linguístico, mas, sobretudo, como forma de pensar e como modo de estruturar o nosso conhecimento sobre o mundo (BRUNER, 1997); sendo assim, a narrativa teria um potencial educativo muito maior do que ser um gênero linguístico, e essa forma de pensar o mundo tem sido utilizada no ensino de ciências (MARTINS; GOUVÊA; PICCININI, 2005; MARTINS et al., 1997). Neste trabalho continuo essa discussão e introduzo as imagens e os desenhos como formas também decisivamente importantes de se pensar e estruturar nossas conceituações sobre o mundo, dando continuidade ao trabalho de Almeida (1990) que, sob o referencial da Gestalt, abordou o papel dos desenhos conjugadamente com as narrativas.

Para uma maior compreensão do tema tratado neste artigo, é necessária uma discussão sobre os raciocínios históricos na Geologia/Geociências, assumindo como referencial teórico a abordagem semiótica em Geologia (PASCHOALE, 1989), e, em relação ao gênero linguístico narrativo, as ideias de Santaella (1996), que compartilha com Paschoale as ideias piercianas. Para a compreensão das relações entre imagem, percepção e pensamento, assumo as ideias da Gestalt (ARNHEIM, 1980, 1987) e introduzo uma discussão da abordagem dos desenhos como linguagem simbólica de Martínez García (2005).

\section{O modo histórico de explicar o mundo da Geologia/Geociências}

A Geologia/Geociências tem contribuído com uma parcela importante para a história efetiva das ciências. Segundo Mayer (1991), os conhecimentos que têm causado grandes impactos intelectuais e culturais em nossas vidas são resultantes de investigações que usaram metodologias históricas e descritivas dessas ciências da natureza. Tais conhecimentos são: sistema solar heliocêntrico, expansão do Universo, evolução orgânica, tempo geológico, placas tectônicas e, mais recentemente, mudança climática global. Adiciona, também, que uma das grandes contribuições filosóficas e metodológicas da Geologia/Geociências para a humanidade é o conceito de tempo geológico, que nos tem ajudado a entender nosso lugar no Universo.

Aqui no Brasil, como nos Estados Unidos (MAYER, 1991), os métodos experimentais ocupam a principal posição no Ensino Fundamental e Médio, porém, concordando com o autor, as mais poderosas ideias sobre nós mesmos e o nosso lugar no Universo são dadas pelos métodos históricos e descritivos, sendo esta uma grande contribuição metodológica da Geologia/Geociências.

Marcando mais firmemente o porquê da minha ênfase em ensinar-pesquisar temas como os deste trabalho, acrescento que a Geologia/Geociências coloca determinantes epistemológicos claros. É ciência histórica e com uma grande ênfase descritiva. Os empiristas enfatizam que, das observações, formulamos os nossos quadros teóricos. Eu quero enfatizar que o conhecimento concreto/observável, o qual será fatual para as explicações, nasce da combinação-conjugação dele próprio, que está para ser constituído na explicação teórica com os instrumentos de indagação ou conceitos formais, que, na maioria das vezes, já são parte integrante e aceitável da própria explicação em construção ou reconstrução constante. 
Para Srour (1978), o conhecimento não é reflexo especular ou duplicação mental da realidade, o conhecimento não 'habita' os objetos a serem conhecidos. A abstração não espelha o real, porém dele se apropria cognitivamente, isto é, modifica, de modo particular, o objeto apropriado; os intelectos são afetados pela nova apreensão dos fenômenos, suas atividades ulteriores são, por isso mesmo, redefinidas. Segundo o autor, o pensamento não trabalha diretamente com o concreto, mas com representações mentais desse mesmo concreto. A matéria-prima da prática cognitiva são abstrações, e não o próprio real na sua concretude.

Produzir conhecimentos é transformar informações complexas (científicas e ideológicas, sensíveis e técnicas) em resultados de um processo abstrato de trabalho, um processo que ocorre na cabeça dos agentes sociais. Trata-se, pois, de uma intervenção intelectual sobre objetos simbólicos (intuições, observações, representações), e não da transformação da própria realidade observada. (SROUR, 1978, p. 36)

Somente assim é possível resgatar a especificidade do pensamento, escapando à confusão empiricista do real com o simbólico. Ensaiando uma exemplificação, porque auxiliará a compreensão de cognições importantes em Geologia/Geociências. O meu gato Laslo é único, singular, histórico e concreto, mas é um ajustamento do ser real com certas características que o enquadram na definição abstrata de gato. Trata-se da transformação dos elementos obtidos (informações simbólicas) numa relação explicativa que assume o caráter de propriedade do objeto em geral. O gato 'em geral' não existe. O gato é um conceito formal e abstrato, que pretende dar conta de todos os gatos singulares que existiram e existirão. Já, a função indicial do signo redobrando o objeto é dada quando o gato significa o Laslo, e não outro. Segundo Paschoale (1990), rastros, pegadas, resíduos, remanências são todos índices de alguma coisa que por lá passou deixando suas marcas. O índice é sempre dual: ligação de uma coisa com outra. Os índices estão baseados nas relações naturais, causais entre os fenômenos e os seres, daí a representação de nuvem ser indicadora de chuva. Já, os conceitos formais não nos dão o conhecimento de um objeto concreto, porém fornecem-nos um conhecimento abstrato de qualquer objeto possível da mesma espécie. O Laslo que é único é dado pela combinaçãoconjugação do conceito de gato com o animal em carne e osso diante de nossos olhos. Os conceitos formais representam, efetivamente, 'instrumentos de indagação', porque aparelham o trabalho teórico e orientam nosso olhar do mundo para a constante construção dos conceitos singulares e dos próprios formais.

Por se tratar de ciência qualitativa e histórica, como a Geologia, o próprio conhecimento que está sendo constituído apresenta um forte componente perceptivo; podemos dizer que temos um continuum entre percepção e pensamento que gera o que Arnheim (1987) tem chamado de pensamento visual. Nas ciências históricas, cujos conceitos singulares são tão ou mais importantes que os formais, o pensamento e a percepção dividem o poder nas elaborações das explicações, daí a riqueza da Geologia/Geociências, onde se, de um lado, é inegável o lado fatual da explicação, ou seja, os objetos concretos que 'afloram' nos trabalhos de campo, nas observações da natureza; do outro lado, a própria explicação já é pré-constituída com o olhar discriminatório, onde padrões, classes conceituais são elaboradas combinatoriamente e conjugadamente, 'criando' história aos dados observados. 
Complementando um pouco mais as ideias sobre a Geologia, ela é casada, em última instância, com o abstrato, com a história. Segundo Paschoale (1990), uma explicação histórica é apenas suposta, não demonstrável experimentalmente. Em outras palavras, a explicação geológica é hipotética no sentido do possível: a relação entre causa e efeito não é conhecida, mas apenas suposta. O processo de hipotetização supõe que o registro (evidência) é um produto de um processo passado, ou seja, as evidências apontadas servirão para a estruturação das hipóteses.

O que direciona o olhar do geólogo são as assunções, as hipóteses e teorias para desvendar a história da Terra. Na natureza, os processos passados, quando resistem à erosão, denudação etc., deixam formas. Como estas formas passam a ser 'formas fixadas', ou seja, vestígios, registros do processo passado?

Essa forma (uma ocorrência concreta perceptiva) é sempre um índice que potencialmente indica um processo, mas qual? Há vários vestígios que não o são para qualquer observador. Não é fácil a partir de um produto (forma) encontrar a sua causa ou os processos que o originaram. Para Paschoale (1990), um dos marcos da pesquisa geológica é a busca não apenas da conexão inequívoca entre produto e processo, mas a busca de uma generalidade presente nestas manifestações, que podem ser chamadas de gestalts. Daí, a busca de uma ordem, de um padrão ser importante. Pois, este padrão estabelece a mediação entre o registro e seu significado, o que é essencial para a formulação da história.

Sabemos que a explicação se faz a partir de uma série de marcas observáveis, e as mesmas só podem ser estudadas por associações e semelhanças com outras feições. Duas cognições são importantes: primeiro, a forma deve ser identificada como significativa, e, para isso, é operado todo um arcabouço de experiências passadas entre feições e informações de processos contemporâneos para capacitar a mente observadora-interpretadora a perceber que tais feições são indicativas (são índices de uma relação físico-existencial apontando para seu objeto de que ele é parte) de um processo passado. A outra cognição, então, é transformar esta forma em 'forma fixada', ou seja, num símbolo que embute códigos que desvendam as relações de causa de sua origem. Esta divisão em duas cognições é artificiosa, porém é importante reter que a procura do registro já direciona as duas cognições. A primeira cognição é mais descritiva e, com o apoio das ideias de Leveson (1988), posso afirmar que é aquela em que o desenho é fundamental para o discernimento de algum padrão. A segunda cognição é mais explicativa, a utilização do padrão discernido serve para dar base fatual à formulação de hipóteses que transformem as formas em evidências de supostas causas de suas origens.

Finalizando, os estudos sobre epistemologia vêm analisando há um bom tempo os modos de explicação próprios das várias ciências, o que é importante para esclarecer as interrelações percepção-pensamento, discurso-raciocínio, imagem-imaginação e conceitos cotidianos-conceitos científicos. As Geologia/Geociências, como ciências naturais, diferem da Física e da Química em sua estrutura conceitual, princípios e metodologia científica. É, das mais importantes, ao trabalhar os processos físico-químicos e a matéria inorgânica e orgânica com escalas espaciais e temporais amplíssimas e diversificadas, descrevendo, formulando e explicando a história do planeta por meio dos raciocínios históricos e visoespaciais. No fazer científico da Geologia/Geociências, a etapa de elaboração de hipóteses e os raciocínios históricos são absolutamente fundamentais. Métodos empíricos, descritivos e históricos são importantes para a compreensão da Terra. Mas, os métodos demarcadores em Geologia/Geociências são os históricos, é ciência histórica da natureza (COMPIANI; PASCHOALE, 1990; FRODE- 
MAN, 1995; PASCHOALE, 1989; POTAPOVA, 1968). Deixo bem claro isso porque tem sido um pressuposto fundamental para os projetos desenvolvidos. Assim, na Geologia/Geociências será importante, nas explicações históricas, a conjugação de discursos verbais, histórico e narrativo, com uma racionalidade visoespacial, que se utiliza de padrões espaço-temporais com uma variedade de imagens: figurativa, formal, animação, documental, de memória etc.

Sobre o discurso narrativo, assinalo algumas ideias que utilizei do trabalho de Santaella (1996). Para a autora, na narração, como a própria palavra indica, o elemento principal é a ação: 'narra-ação'. Trata-se, assim, do registro linguístico de eventos ou situações de acontecimentos singulares em termos de agente/paciente e causa/efeito. Define o discurso narrativo sucessivo como a apresentação sequencial ou cronológica das partes de um dado evento, e o narrativo causal, quando um determinado evento é relacionado a fatos, estabelecendo-se relações de causa e efeito de implicações lógicas, e não apenas cronológicas. Claro, um discurso pode conter as duas características e, assim, ser narrativo sucessivo-causal. Essa narrativa apresenta uma lógica em que os detalhes constituem-se partes integradas na estrutura geral da explanação. Esse é um tipo de discurso geocientífico e, por isso, é essa noção de sucessão no tempo e de implicações causais de um evento que exercitamos com esses alunos.

A explicação histórica dos geocientistas, cuja base epistemológica acabei de discutir resumidamente, visa explicar como ocorreu um evento do passado da Terra por meio de 'marcas' observáveis do evento, que supomos ser evidências ligadas aos processos ocorridos. Ou seja, partimos dos produtos, de imagens de vestígios, dos efeitos de um acontecimento, para buscar as suas causas. É essa racionalidade do efeito para a causa que foi exercitada com esses alunos de diferentes modos. Queremos desvendar um fenômeno com espaço e tempo indissociáveis. A marca, a forma é crucial nesse vestígio, então, trabalhamos com percepção e pensamento de modo indissociável (Gestalt), como, também, o visual e o verbal. A ideia, em absoluto, não é a de criar dicotomias, mas de uma separação estratégica ou didática, acreditando em uma melhor compreensão das complexidades envolvidas, até porque os processos de elaborações de conhecimentos mais generalizantes e histórico-espaciais são contínuos e descontínuos entre contextualização e descontextualização e síntese e análise. Em outras palavras, conjugadamente e indissociavelmente, contexto e síntese estão mais ligados à percepção, espaço e imagem; e descontextualização e análise, ao pensamento, tempo e discurso. Em resumo, penso que posso tratar como tendo mais afinidades: visual, percepção, espaço e imagem; e por outro lado: verbal, pensamento, tempo e discurso.

Nesse artigo, vou também discutir quanto o desenho é fundamental para o discernimento das formas que são tão relevantes para a elaboração da explicação histórica e do padrão visoespacial do fenômeno. Segundo Leveson (1988), para desenhar ou criar um esquema, deve-se olhar, ver e tomar decisões. Uma imagem desenvolve-se. Existe um contínuo questionamento e resposta, avaliação e reavaliação. Para o autor, é por meio do desenho que alguém aprende a ver e a visão se torna acurada. Vou trabalhar com imagens, sobretudo, desenhos ou imagens mais figurativas do que formais. Neste artigo, inicio a elaboração de novas matrizes de indagação nas quais terá papel destacado a imagem e suas relações com a percepção e síntese, suas inter-relações em como os objetos e espaços são significados e construídos, como, também, o destacado papel dos raciocínios espaciais na simbolização de formas/objetos e espaços e contextos. Nossas pesquisas, além de buscarem um olhar mais próprio para a linguagem visual, associam essa linguagem às suas relações com espaço, contexto e lugar. 
Na primeira experiência, diante de uma imagem estática (Figura 1) que representa um tipo de congelamento do real de diferentes ambientes geográficos, os alunos foram colocados para descrever essa paisagem e a própria paisagem suscitou a busca das causas que teriam gerado aquela paisagem. Partem do efeito, a paisagem, em busca de causas possíveis de serem compreendidas com os poucos vestígios constantes na própria paisagem ou em seus repertórios de conhecimentos anteriores. Os alunos exercitaram a observação, a percepção de relações espaciais da paisagem estática, pintaram o deseho (Figura 2) e elaboraram suas explicações de forma verbal. Na segunda experiência, a partir de um problema real, o córrego poluído e abandonado, os alunos buscam as causas históricas realizando trabalhos de campo na região e entrevistas com os moradores (memória oral). Partem da observação dinâmica de feições de degradação atuais para responderem quais seriam as causas passadas. O foco das observações é perceptivo e o foco das explicações é verbal. Buscam-se cognições mais sintéticas, com uma compreensão contextual e histórica do problema, mas os resultados são solicitados somente de forma verbal, como na primeira experiência. Na terceira experiência, os alunos vivenciam uma visita estruturada em uma estação de tratamento de água de uma grande cidade. Eles são postos diante de um conjunto estruturado de agentes, partes e processos do tratamento. Após a visita, com a memória e incentivando o uso do visual e imagens, as professoras de Português e Artes solicitam que os alunos ressaltem o que foi mais importante da visita (Figuras 3 e 4). Com o foco no visual, os alunos desenham narrando o trabalho de campo ocorrido, eles olham para o passado vivido e buscam os elementos referenciais que poderiam ser transformados em elementos generalizantes que conceituem a experiência vivida.

\section{Experiências de ensinar/aprender a ver, desenhar e narrar com Geologia/Geociências no Ensino Fundamental}

Compartilhando com as ideias de Menezes (1997), ler e escrever são coisas que passamos a fazer com o aprendizado. Não é nada natural saber ler, todos sabem que ler é fruto de um longo processo de aprendizagem. Já a percepção de que existem diferenças entre ler e compreender não é tão imediata assim, mas ainda é fácil de entender. A visão, talvez por ser nossa relação imediata com o mundo, que dá sentido e referência a nossos atos mais cotidianos e irrefletidos, é tida, geralmente, como um atributo natural e biológico. Quantos de nós já colocaram em dúvida a sua capacidade de ver? Sabemos ver? Seria nossa visão isenta de pressupostos? É de fácil compreensão que aquilo que sabemos ou aquilo que julgamos, ou o contexto da situação, afeta o modo como vemos as coisas? Os gases expelidos por uma siderúrgica serão interpretados, por um transeunte, como cheiro de ovos podres, e, por um químico, como dióxido de enxofre. Como no processo de compreensão da linguagem escrita, também, na linguagem visual, vários níveis diferenciados de apreensão são possíveis perante uma coisa, um fenômeno ou uma mesma obra. Nossa compreensão do que vemos depende de nossa capacidade de perceber o que está incorporado na constituição de uma imagem, seus conceitos, suas referências, enfim, instaurar um 'diálogo' para perceber a profundidade de suas implicações. Não é imediata a percepção de que, da mesma forma que aprendemos a ler, devemos também aprender a ver.

Há um modo enraizado do pensamento cotidiano que é: o que não se percebe não se concebe. Somos espontaneamente realistas. Como aponta Chaui (1995), esse nosso realismo é 
entrelaçado com nosso subjetivismo na crença ancestral de que a visão depende de nós, muito mais do que dependeria das coisas. Ela exemplifica que, diante de algo horrendo, fechamos os olhos para torná-lo inexistente, ou, quando a criança pequenina começa a aprender a brincar de esconde-esconde, rimos porque fecha os olhos, certa de que, ao fazê-lo, os outros deixam de vê-la porque ela deixou de vê-los. A autora comenta como o olhar, agora com seu sinônimo visão compõe diversas palavras, sempre com a ideia de que cremos nas palavras, e nelas cremos porque cremos em nossos olhos, cremos que as coisas e os outros existem porque vemos e que os vemos porque existem. Como exemplos, comenta que ao falar em visões de mundo nos referirmos a diferenças culturais ou ideológicas, ao mencionar re-visão pretendemos tratar de mudanças de ideias, correção do rumo do pensamento ou da escrita, sem nos indagarmos por que referimos, ao olhar, quando tratamos de alterações de ideias, convicções, práticas ou dizeres. Se essas crenças acima já estavam profundamente arraigadas no cotidiano humano, o que será com a nova oralidade da atual sociedade de massas que, segundo Almeida (1994), é para pessoas que estão longe da leitura e da escrita como práticas cotidianas, e, para estas, é produzida uma cultura transmitida em imagens e sons que implica uma inteligência reflexa, especular, mecânica; o que se vê e se ouve é o que é, uma verdade, mesmo que esta seja substituída por outra em seguida, nunca compondo um todo que dê sentido ao pensamento sobre o mundo.

Jameson (2006) diz que a globalização da informação, a supersaturação de imagens e a hipermidiação do real provocam um tipo de disseminação do poder em nova escala global, devido ao domínio de toda uma alta tecnologia de representação e reprodução. Saturação por mercadorias e a extraordinária simultaneidade informacional pós-geográfica e pós-espacial que tece uma teia mais fina, minuciosa e penetrante de sentidos que querem que nos escapem. Mas precisamos enfrentar essas novas situações justamente para interferir e participar do poder. As mudanças são cada vez mais rápidas, embora possuídas por uma maciça permanência de que a atuação humana, seja individual ou coletiva, é, cada vez mais, irrisória, devido a uma gigantesca intensificação dos processos cibernéticos atribuídos ao conhecimento científico e tecnológico.

E a escola tem algum papel nisso tudo? Mais especificamente no ensino de ciências, a Geologia/Geociências pode contribuir para uma alfabetização do ler e ver?

As experiências a serem apresentadas foram desenvolvidas junto aos dois projetos de formação continuada com a escola básica pública da cidade de Campinas. Vou utilizar, como divisão dos subitens, as disciplinas escolares trabalhadas.

Todas as atividades envolveram os alunos em observações detalhadas e, depois, com solicitações de descrições ou explicações gerais do que haviam observado. A primeira experiência solicitou a observação de uma figura estática, depois, a reprodução da pintura da figura, com posterior descrição. Na primeira experiência, não houve um trabalho com um lugar real e, sim, a partir de uma figura, foram exercitadas: percepção, análise e síntese da imagem, e posterior expressão e representação por, principalmente, linguagem verbal. A segunda experiência foi um trabalho mais longo e duradouro a partir de/e focado nos problemas do abandono do córrego ao lado da escola, que exigiu dos alunos várias cognições, dentre elas: observação, comparação, análise e síntese. Na segunda experiência, houve um trabalho com o lugar real, exercitando-se várias formas de obtenção de dados e interpretações, tais como: trabalho de campo, entrevistas, fotografias e leitura de textos. As interpretações finais foram elabora- 
das, sobretudo, com o verbal. Nessa atividade, como na terceira que vou discutir, houve trabalhos de campo, ou seja, observaram um ambiente real, complexo, com conflitos e históricogeográfico. Na terceira atividade, após um trabalho de campo, foi solicitado, na disciplina de Português, que os alunos escrevessem e desenhassem o que mais lhes havia chamado a atenção na visita realizada. Já na disciplina de Artes, foi solicitado que desenhassem. O foco nessa terceira experiência foi a capacidade de uma narrativa sintética de um processo já passado mas vivido, como, também, a linguagem visual e seus desenhos.

\section{Atividade desenvolvida na disciplina de Português}

A atividade foi desenvolvida no segundo semestre de 1998, com alunos de uma $6^{a}$ série diurna com 22 alunos, sendo 14 meninas e oito meninos. A atividade proposta pela professora de Português foi a de que os alunos, primeiro, pintassem uma fotocópia de paisagem geográfica conforme a Figura 1 do Átlas visual da Terra (Guizzo, 1996), buscando reproduzir as cores da imagem colorida original. Depois, foi solicitado que eles fizessem uma descrição da paisagem e dessem um título à redação.

Alguns resultados são interessantes e desafiantes para se discutirem os problemas relacionados à leitura, compreensão e expressão de ideias geocientíficas ${ }^{6}$.

Os resultados apresentados foram analisados com base em duas perspectivas: compreender a escrita, como ponto de vista dos alunos a partir da imagem geográfica, e discutir as relações entre gêneros linguísticos e explicações geocientíficas.

A tarefa solicitada foi uma descrição de uma representação de paisagem geográfica (Figura 1). Ao analisarmos os textos e reproduções pintadas dos alunos, encontramos uma variedade de redações contendo dois gêneros linguísticos: a descrição e a narração.

Uma mesma redação pode apresentar apenas um gênero linguístico ou mais de um, por exemplo, apresentar um texto descritivo indicial e narrativa sucessiva. O modo e o sentido do texto escrito também foram importantes, redigem das partes para o todo e de cima para baixo; outros detalham aspectos da imagem sem um sentido claro de leitura ou redação; alguns caminham de uma impressão do todo, de uma qualidade, para algumas partes que mais lhes chamaram a atenção. Seguem exemplos da atividade proposta.

Exemplos de descrição - A do tipo indicial: "Posso ver que tem dois rios e que um dos rios passa de baixo da ponte na direita do desenho e posso ver também que tem muitas plantações e muito verde e é só isso que eu vejo" "Trata-se de um tipo de representação que dirige imediatamente a retina mental do receptor para o objeto em questão, objeto que, dissecado pela linguagem verbal, passa a ser composto em partes que indicam o todo. Já a descrição qualitativa: "Eu vejo neste desenho muito verde que é o gramado do terreno porque o verde que está todo espalhado pelo terreno, vejo também as árvores que são verde, vejo o rio que é azul mas é pouco vejo mais o verde e é só isso que eu vejo de toda a imagem". Esse aluno fez

\footnotetext{
${ }^{6}$ Para mais detalhes, ver Teixeira; Compiani; Newerla (2006).

${ }^{7}$ Os textos estão como foram escritos no original pelos alunos.
} 
Compiani, M.

a pintura constante da Figura 2 e colocou, como título, 'A vegetação'. Trata-se de uma certa busca da essência do todo, quando uma qualidade é ressaltada e descrita como o centro das atenções. Isso foi feito de tal modo, que o aluno não reproduziu as cores originais da figura e as transformou em verde, como um símbolo da vegetação, título de sua descrição.

Figura 1. Paisagem do livro Atlas visual da Terra

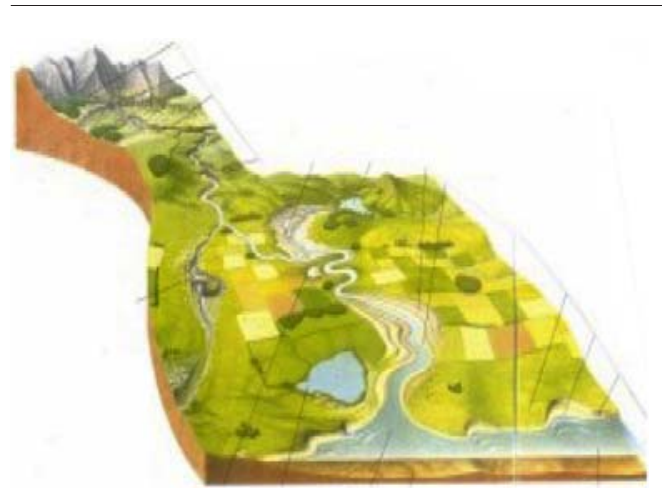

Fonte: ATLAS visual da Terra (Guizzo, 1996)
Figura 2. Pintura de um aluno

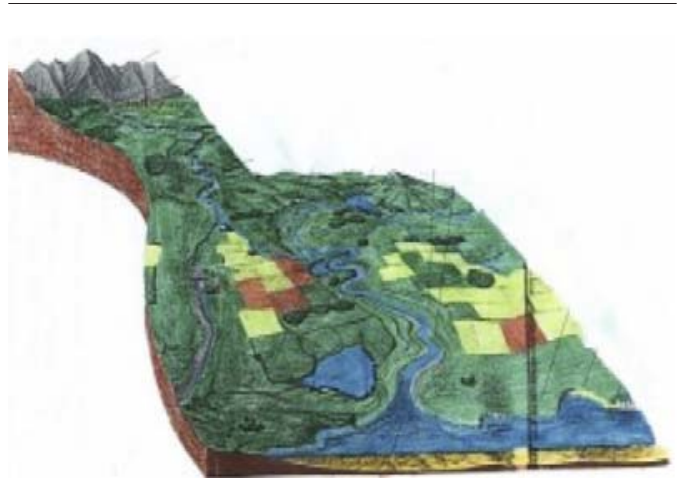

Fonte: pintura feita por aluno da escola estadual.

Exemplos de narrativas - A narrativa sucessiva: "Tem uma nacente perto das montanhas que formou lagos e com algum tempo se transformou em vários rio que foi descendo o terreno até chegar no mar". Narra com uma ordem cronológica e há um encadeamento linear, ou seja, um fato acontecendo após o outro. A narrativa causal: "Podemos observar que tem muitas montanhas no começo do desenho e perto das montanhas nasce um rio que vai descendo porque ele não pode ficar parado e precisa chegar no mar só que antes o rio vai se esparramando pelo verde e vai molhando". Narrativa que pressupõe, sempre, um julgamento avaliativo de uma ação sobre a outra, ou seja, ela estabelece uma relação de causa e efeito, de implicações lógicas, e não apenas cronológicas.

O exercício solicitava a descrição da paisagem, porém várias redações são narrativas ou misturam ambos os gêneros linguísticos. Por que isso, se, na narração, como a própria palavra indica, o elemento principal é a ação: narra-ação? A narração trata, assim, do registro linguístico de eventos ou situações de acontecimentos singulares em termos de agente/paciente e causa/efeito. As narrações encontradas foram: a sucessiva e a causal. A classificação da descrição e da narração foi baseada em Santaella (1996), e estão explicadas no item anterior. Provavelmente, isso se deu porque o objeto de leitura - uma paisagem com diferentes espaços e processos geográficos - gerou essa necessidade de explicação dos processos visíveis, cuja descrição - que é uma tentativa de se traduzirem, pelo verbal, caracteres, formas e atributos qualitativos que os sentidos captam - não deu conta de processos visíveis, que necessitaram da narração para uma melhor explicação das causas da origem e movimento do rio para o mar, por exemplo. 


\section{Breve discussão}

Como as redações dos alunos mostram, ver e descrever apresentam ambiguidades. As representações da natureza não são dadas e objetivas e a sua leitura isenta de várias interpretações. Nossos sentidos não são apenas 'janelas' para o mundo exterior. A intervenção da mente humana na percepção-interpretação de um fenômeno não é uma atividade de natureza passiva. Isto é, a mente exposta a uma 'chuva de perceptos' do exterior, simplesmente, os receberia e interpretaria, ficando a eficácia desta atividade controlada tão somente pela nossa capacidade de bem observar ou de elaborar bons experimentos. Há uma dualidade interessante entre a experiência perceptiva e a nossa compreensão do mundo que aflora tanto no discurso científico quanto no cotidiano; e um dos palcos privilegiados para administrar essas questões é a sala de aula (EDWARDS, 1998).

Se ver o mundo aparente das coisas foi traduzido, por meio do verbal, pela descrição, parece que a narração surgiu de uma necessidade cotidiana de buscar explicações para o observado, ou o objeto geocientífico suscitou o leitor/redator a constituir explicações de causalidade e narrativas. Uma hipótese para explicar isso pode ser o fato de que as narrativas, provavelmente, atuam mais como forma de pensar e como estrutura para organizar o nosso conhecimento do que como tipo linguístico descritivo ou narrativo. Há um campo de interface interessante entre Português e Geologia/Geociências com relação às narrativas. Bruner (1997) diz que as narrativas, mais do que gêneros de discurso, são formas de conhecimento que estruturam o nosso pensamento tanto quanto os raciocínios lógico-matemáticos. Em outras palavras, nós observamos o mundo e o explicamos pelas narrativas e raciocínios lógico-matemáticos. Isso nos parece bastante instigante e abre um campo de pesquisas amplo entre Geologia/Geociências e as linguagens, sobretudo pelas características das explicações geocientíficas que apresentam uma lógica narrativa (FRODEMAN, 1995).

Outra hipótese é a de que isso se deve ao grau de identidade dos gêneros linguísticos, muito utilizados em Português, com os gêneros das explicações geocientíficas que lidam, em suas explicações dos fenômenos terrestres, com as descrições, as narrativas sucessivo-causais e o argumentar histórico. Identidade que é mais ampla, pois esses estilos narrativos são dos geocientistas, dos historiadores e parte fulcral dos contos policiais e da narrativa cotidiana, já que buscam explicar fatos já acontecidos. Desenvolver pesquisas nesse sentido é importante, uma vez que as narrativas têm um potencial educativo muito grande no ensino de ciências (MARTINS et al., 1997).

\section{Atividade interdisciplinar entre Português e Geografia}

O trabalho foi desenvolvido pelas professoras de Geografia e Português no primeiro semestre de 1998, com uma sétima série com 36 alunos do período noturno que partiu da própria realidade do entorno da escola e dos alunos ${ }^{8}$. Trata-se de uma tentativa de atuação

\footnotetext{
${ }^{8}$ Para mais detalhes, ver Picciuto e Silva (1999).
} 
interdisciplinar que buscou uma percepção mais aguçada da região em que se insere a escola e na qual vive a grande maioria dos alunos. A intenção era obter textos consistentes, em que os alunos pudessem descrever, narrar e dissertar ao mesmo tempo, argumentando com fatos relevantes de suas vidas e para elas. Pretendia-se demonstrar que é uma boa abordagem partir do local para o geral, uma vez que a localidade encerra questões da globalidade e, a partir destas, pode-se construir um vaivém entre local e global, particular e geral, singular e histórico.

Usando o tema "água, um recurso natural vital" como conceito estruturante da aprendizagem, procurou-se enfocar o córrego localizado dentro do bairro, o qual é parte de um problema constante na vida desses estudantes, fazendo a ligação entre o lugar, a região, com os conceitos geográficos e os conteúdos de português. Pretendeu-se mostrar que esse córrego relaciona-se com o contexto urbano de Campinas que, por sua vez, faz parte de um universo maior, o de uma região industrializada no Brasil.

A primeira atividade realizada foi solicitada pela professora de Geografia: consistia em levantar as informações que os alunos possuíam sobre o passado do bairro, para, assim, poder discutir as mais recentes transformações. Pediu-se para que registrassem, individualmente, suas memórias a respeito das transformações ocorridas no bairro onde eles residiam. As transformações mais citadas foram a implantação e habitação da Vila União, bairro vizinho ao da escola, que os alunos conhecem, já que começou a ser ocupado há pouco tempo, além da construção de um hipermercado. Para os alunos, de todas as transformações ocorridas, a única considerada negativa era a degradação do córrego: "E o córrego antigamente era limpo e foi ficando sujo." "As pessoas jogam lixo e animais mortos e quando chove não aguentamos o mau cheiro."

Houve a realização de um trabalho de campo no entorno do córrego, com um roteiro de atividades composto por duas partes. Na primeira, os alunos deveriam fazer uma descrição do que viam e responder a algumas questões, como: você observa lixo no córrego? Que tipo de lixo? $\mathrm{Na}$ sua opinião, qual motivo leva as pessoas a jogarem lixo no córrego? A segunda parte era composta por entrevistas com os moradores, procurando levantar os seguintes dados: como se deu a ocupação do local; como era o convívio das pessoas com a área; qual a opinião dos moradores sobre a canalização do córrego; o porquê do esgoto e lixo serem jogados diretamente no córrego.

Nas aulas de Português, esses textos eram refeitos, ou seja, ao mesmo tempo em que eram produzidos, também eram lidos e discutidos pelos alunos. Isto aconteceu em etapas. Num primeiro momento, o trabalho foi desenvolvido com os textos sobre a memória do bairro, mas, depois, prosseguiu com todos os outros textos. Eram lidos e, a partir daí, organizados para melhorar aquilo que o aluno queria expressar. Trechos de alguns textos eram colocados na lousa e, junto com os alunos, corrigidos. Depois, os estudantes faziam a leitura trocando os textos entre si. Nesse momento, cada aluno ficou na condição de leitor do texto de um colega, texto próximo daquilo que ele é capaz de escrever e, portanto, capaz de detectar possíveis erros e soluções para melhorar a estrutura de seus textos. A ideia era ensinar lendo, refletindo e discutindo seus próprios textos, pois, dessa maneira, eles poderiam socializar os conhecimentos antes não sistematizados, mas que, aos poucos, se transformariam em significados que poderiam ser utilizados por eles.

Além da escrita e das observações da área, havia outras atividades, como: desenhos, as citadas entrevistas e fotografias. Cada aluno teve a opção de fotografar o que mais lhe desper- 
tasse a atenção, uma vez que a fotografia foi um registro importante para a socialização dos estudos de campo em sala de aula, já que marcou a degradação do local visitado e contrastou com a história dos antigos moradores contada nas entrevistas (Córrego com águas limpas).

De posse do material colhido, a discussão sobre os bairros - o da escola e o de suas casas - veio por meio desses textos, em que os alunos começaram a relacionar as questões geocientíficas e ambientais, anteriormente discutidas, com o problema local, fazendo a síntese a partir das informações obtidas no trabalho de campo. Apresentaram uma narrativa não apenas sucessiva e, sim, com elementos de causalidade entre as causas e efeitos dos eventos relatados. As semelhanças são nítidas com o discurso dos geocientistas e, também, dos historiadores, que se utilizam da narrativa sucessiva-causal, como se pode ver abaixo na síntese feita por um dos grupos de alunos da classe intitulada 'A história do bairro a partir do córrego'.

Constataram em entrevistas com os moradores: "As casas (ou terrenos) do Bairro J. S. Lúcia, que contornam o córrego, não foram doados, foram todos comprados."

Levantam uma hipótese: "Mas quem compraria uma casa de frente com um córrego tão sujo e fedido?"

Argumentam sobre a mesma: “O caso é que, o córrego, ou seja, a água do córrego era limpa, segundo os moradores limpíssima."

Voltam ao acontecimento (a poluição do córrego): "E foi sujando com o tempo."

Buscam as causas: "Com a falta de conscientização dos moradores e com a falta de ajuda da prefeitura porque o lixeiro não passa nessa rua para pegar o lixo e porque a lixeira fica muito longe."

O texto é narrativo porque, como o próprio título sugere, conta a história do bairro, e argumentativo porque os alunos dialogam com ele, formulando hipóteses de acordo com o material coletado em campo.

Foi possível verificar a ideia de Scott (1992) de que a narrativa é uma linguagem corriqueira em nosso cotidiano. As entrevistas com os moradores e os primeiros textos curtos e fragmentados, que geraram os textos finais mais sintéticos, já eram organizados pela lógica da narrativa. Todos os textos apresentados são narrativos, com partes mais descritivas ou argumentativas. O eixo dos textos é a lógica narrativa. Foi possível constatar que os alunos apresentaram uma narrativa não apenas sucessiva e, sim, com elementos de causalidade entre as causas e efeitos dos eventos relatados. As semelhanças foram nítidas com o discurso dos geocientistas e, também, dos historiadores. Estes, quando explicam a história de um evento, utilizam a narrativa sucessiva-causal. Tal narrativa expressa o encadeamento cronológico das partes de um evento, estabelecendo, entre elas, implicações lógicas de causa e efeito.

\section{Breve discussão}

Essa experiência mostra-nos quão interessante foi o trabalho fora da sala de aula para conseguir uma maior participação dos alunos, fazendo-os sentirem-se mais próximos do contexto proposto. Poder vivenciar a área objeto de estudo fez uma grande diferença. A observação e contato com a área estudada tornou possível a comparação das diferenças do local, possibilitou perceber o impacto ambiental sofrido pelo tipo de ocupação feita. O resultado do trabalho de campo ficou evidenciado na criação e elaboração dos textos. 
A professora de Português conseguiu, com este trabalho, desenvolver a narrativa e contribuir decisivamente com a argumentação geográfica, pois esta se faz através da análise do local e do bairro. A professora de Geografia potencializou um aspecto dos Parâmetros Curriculares Nacionais, que é trabalhar com o local e fazer pontes com a história da urbanização e o ensino sobre bacia hidrográfica.

A interdisciplinaridade contribui para os avanços porque uma disciplina sem a outra não teria conseguido a realização idealizada para o trabalho, e o grande integrador foi o trabalho de campo e a lógica narrativa para as explicações elaboradas. De acordo com Heckhaisen (2006), existem vários tipos de interdisciplinaridade. Acredito que o trabalho se insere no que ele define como interdisciplinaridade estrutural, que é aquela na qual determinadas áreas de estudo interagem, trocando informações para que, ao se estudar determinado problema, haja a convergência destas áreas de estudo envolvidas na busca de ações eficazes para a solução deste problema.

Nesta atividade de ensino, as disciplinas de Português e Geografia agiram ao mesmo tempo com trocas de informações, se interpenetrando em seus campos de ação para que os alunos estabelecessem uma relação de sentidos. Sentidos esses que forneceram saltos qualitativos para que entendessem o local onde vivem e se percebessem como agentes modificadores de sua própria realidade, construindo os conceitos pela 'fusão' entre o que já conheciam do bairro (pelo seu saber cotidiano) e o que lhes foi acrescentado (por meio do saber sistematizado). Também, a ideia foi trazer para dentro da sala de aula o contexto geográfico, histórico e cultural em que se insere a escola. Há toda uma cultura escolar de transmissão de informações baseadas em definições e conteúdos descontextualizadas e sem maiores aberturas para relações entre disciplinas e o mundo cotidiano. O conteúdo da maioria dos livros didáticos é generalista e descontextualizado, não havendo preocupação de trabalhar com níveis mais complexos de conceitos e problemas a partir de, e em integração com, o contexto em que se inserem a escola e os alunos.

Se a escola não trabalhar com a visão do aluno em relação aos fenômenos do seu meio, por exemplo, como os córregos do meio urbano, não desenvolverá, sobre os problemas relativos a estes fenômenos, uma reflexão que, muitas vezes, resulte em soluções para estes problemas. Esta visão, este olhar deve ser tratado sobre vários prismas, com a inserção de um número maior possível de disciplinas; quanto maior a diversidade de linguagens usadas e a possibilidade de interação de todos os alunos com essa realidade, mais o aluno dialogará, no trato desses fenômenos, com uma visão mais abrangente e interpretativo-crítica.

\section{Atividade interdisciplinar entre Português e Artes}

O trabalho foi desenvolvido pelas professoras de Matemática, Português e Artes, junto a uma quinta série com 28 alunos do período diurno, no primeiro semestre de 2009. Trata-se de uma tentativa de atuação interdisciplinar que buscou um trabalho mais integrado entre as linguagens verbal, visual e matemática, sem o estereótipo de que à disciplina de Português cabe o verbal e às Artes, o visual. Para este artigo, vou discutir apenas os desenhos que foram feitos após uma atividade de campo onde os alunos foram conhecer a Estação de Tratamento de Água da Companhia de Tratamento de Água (SANASA) do Município de Campinas, SP. Com as atividades fora e dentro da sala de aula, a ideia era trabalhar percepção/ 
observação e interpretação/compreensão com elaborações de representações verbal e visual. Exercitou-se o papel da percepção, da análise e da síntese, como cognições importantes no ensino-aprendizagem com lugares reais, contextos interessantes e motivadores, nos quais a imagem é relevante e parte fulcral das conceituações elaboradas.

Desse modo, trago, para debate, mais duas figuras, as 3 e 4; a 3 foi feita na disciplina de Português e a 4 na disciplina de Artes. Na Figura 3, a tarefa em sala de aula consistiu em uma pergunta: 'Escreva o que mais lhe chamou atenção no tratamento da água na SANASA e por quê?’ A professora, oralmente, incentivou que eles utilizassem também o desenho.

A resposta escrita do estudante está a seguir: "O que mais me chamou a atenção foi como eles cuidam da água, porque se eles não cuidassem da água nós não beberíamos, não tomaríamos banho e por fim nós morreríamos, não somos nada sem a água".

O desenho da Figura 3 é muito sintético e analítico, com a aluna mesclando imagens com escrita. Destaco que, nesse caso e no próximo desenho da Figura 4, inverte-se um uso das linguagens, uma vez que a escrita foi posta para atestar o desenho ao invés do uso corriqueiro do desenho ilustrar a escrita. O desenho é muito conceitual, pois a aluna inseriu sua visita à SANASA no contexto mais geral do tratamento e uso de água em uma cidade, já que começa seu desenho com um signo (rio) de onde viria a água para ser tratada, destacando, na parte central do desenho, os principais processos de tratamento que tornarão a água potável para a cidade, representada por retângulos ${ }^{9}$. A tônica do desenho com escritas e a mensagem que quer passar é muito mais poderosa de sentido do que a resposta escrita, na medida em que destaca o conceito de um ciclo (inclusive, com uso de flechas) que começa da água do rio, seu tratamento até o uso, nas cidades, da água potável. Há uma interessante conjugação da ideia sintética do todo, o ciclo, com uma parte essencial do todo, que é o desenho principal (Figura 3a) com os processos de tratamento e filtragem para tornar a água potável.

Figura 3. Foto dos tanques de tratamento de água e desenho de aluna do $5^{\circ}$ ano feito em sala de aula na atividade de Português, após a visita escolar realizada na SANASA.
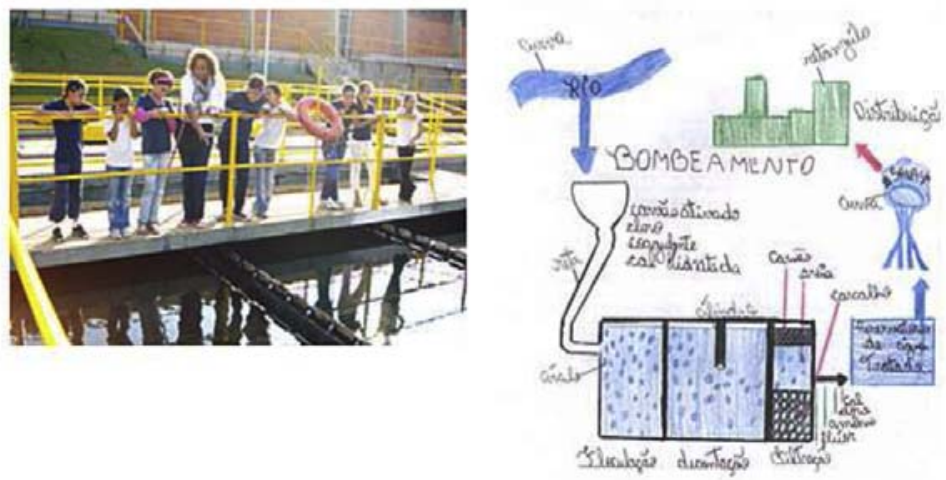

Fontes: Desenho feito por aluna da E.E. Adalberto Nascimento e foto de Barbosa, M. A.

${ }^{9}$ É interessante assinalar que, no desenho, há escritas de formas geométricas, tais como curva, círculo etc.; isso decorre de que, em Matemática, estudavam Geometria e o meio ambiente. Para mais detalhes da participação da Matemática nessa experiência, ver Compiani (2011). 
Compiani, M.

Figura 3a. Detalhe do desenho mostrando um perfil da estação de tratamento de água com suas principais partes.

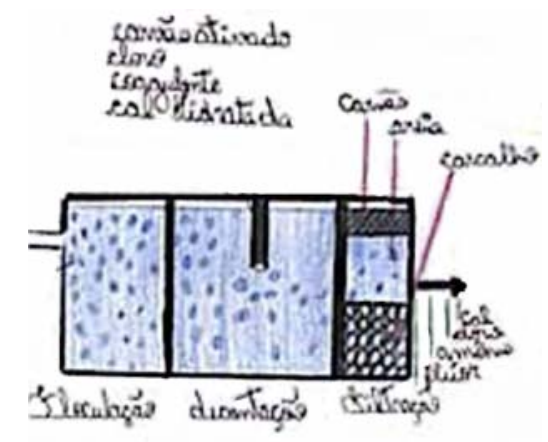

Fonte: Desenho feito por aluna da E.E. Adalberto Nascimento.

$\mathrm{Na}$ Figura 3a, podemos ver como essa compreensão dos processos foi tão importante para a aluna, uma vez que ela os desenha com detalhes e especificando, particularizando com a escrita. A escrita associada à imagem tem o sentido de indiciar e contextualizar, já que é o desenho da estação de tratamento específica visitada com seus diferentes processos de separação de misturas: floculação e decantação, seu processo de filtração com areia, carvão, cascalho, e seus elementos para a potabilidade da água (cal, cloro, amônia e flúor). A generalização está em sua maior capacidade conceitual de inserir esse específico tratamento de água no ciclo maior de funcionalidade do tratamento e uso da água em uma cidade. Isso ela faz criando o ciclo pelo desenho. Ela mescla sentidos do contexto específico da SANASA com o contexto mais geral.

$\mathrm{Na}$ Figura 3, há dois aspectos que se destacam: se o foco for para o continente, vamos enxergar um ciclo de tratamento de água para uma cidade; se o foco for para o centro da figura, vamos ver com detalhe (Figura 3a), em forma de perfil, os processos específicos do tratamento de água da SANASA. Destaco a forma de perfil na medida em que isso exigiu da aluna uma maior abstração e criatividade na adequação do observado em campo com um desenho que representasse a sua compreensão dos processos de tratamento. Ao optar pelo perfil, ela criou uma imagem de como seriam os tanques de separação em profundidade, uma vez que o desenho representa um processo não visível (pela foto, sabemos que eles viram a superfície dos tanques). A maioria dos alunos desenhou os tanques em forma areal, na perspectiva vertical de olhar de cima, conforme a Figura 4a. Além dessa maior abstração, ela foi inventiva ao adequar, no perfil, o processo de filtração (lado direito do perfil) com os processos de separação. Na visita à SANASA, eles viram na perspectiva horizontal, ou de perfil, o processo de filtração. Assim, ela criou o perfil dos processos de separação química ajustandoo ao perfil de filtração. 
O perfil, no ensino de ciências ou geografia, é utilizado para se fazer um corte transversal do tempo e espaço de um fenômeno. A aluna transferiu uma certa gestalt ou estrutura de suporte, que é o perfil, para o processo de tratamento d'água. Entre outros, é esse tipo de experiência visual, uso e cognição da imagem, que me interessa investigar na escola.

As relações forma/fundo (Gestalt) e objeto/contexto (MARTÍNEZ GARCÍA, 2004) nos orientam para a compreensão desses dois aspectos principais do desenho: o continente mais geral e descontextualizado do ciclo do tratamento de água em uma cidade, e os aspectos mais específicos e contextualizados dos processos de tratamento da SANASA, como o perfil e a caixa d'água do bairro. Esses dois aspectos criam um contexto espacial e narrativo do conjunto simbólico do tratamento de água. Esse tipo narrativo é mais marcante na Figura 4.

Figura 4. Desenho de aluno representando os setores do tratamento d'água da SANASA realizado na disciplina de Artes.

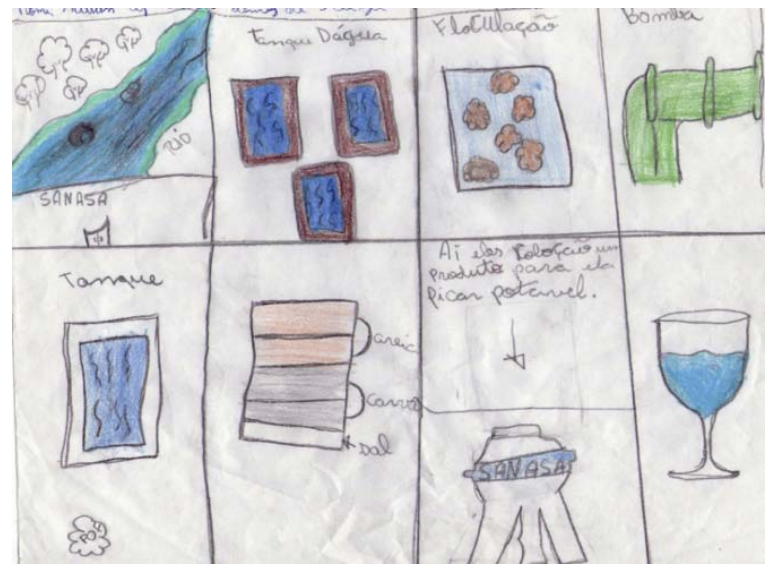

Fonte: Desenho feito por aluno da E.E. Adalberto Nascimento.

Figura 4a. Detalhe do tanque visto na perspectiva vertical e representado de forma areal.

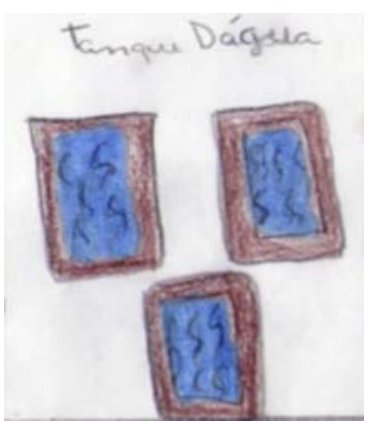

Fonte: Desenho feito por aluna da E.E. Adalberto Nascimento. 
Os desenhos ora são mais generalizantes, e é a escrita que especifica, ora são mais singulares, sem a escrita ou com a escrita generalizando. Essa complexidade de usos de formas/objetos integra-se com o espaço, e estes constituem o contexto espaço-temporal. No uso das imagens, de um modo geral, os enunciados, quando utilizados, são secundários. A linguagem visual foi decisiva para uma maior e complexa significação dos diferentes pontos vistos na visita de campo na SANASA.

$\mathrm{Na}$ Figura 4, a atividade consistia em desenhar, em uma página A4, o que mais chamou a atenção dos alunos na visita à SANASA. Destaco que o aluno o fez como se estivesse contando uma estória para a família, resposta mais característica para a disciplina de português. Num trabalho interdisciplinar, as barreiras vão sendo rompidas e adquirem outras posições. Nas Artes, aparecem estórias em forma de narrativas visuais, e, em Português, surgem desenhos que expressam e explicam as principais ideias, com desenhos conceituando tão ou mais que as palavras, comumente usadas em Português.

O desenho todo, a história em quadrinhos, busca os elementos representativos singulares e generalizantes de cada setor do tratamento d'água da SANASA sem perder de vista, no referente visual, a singularidade e os elementos essenciais de cada setor, e no conjunto do tratamento de água, a possibilidade de uma representação generalizante; esta conseguida por meio de uma narrativa com quadrinhos desenhados com algumas legendas. Usualmente, as generalizações são comandadas pela análise e seus enunciados escritos; nesse exemplo, a síntese das representações imagéticas está comandando as cognições (elaboração, escolha das partes mais significativas e uso das diferentes linguagens) e o conhecimento (narrativa sobre o tratamento da água). As imagens são determinantes e constituem o corpo explicativo da narrativa. O conjunto visoverbal representa cada setor e o tratamento de água da SANASA. Por outro lado, a sequência narrativa de quadrinhos constitui-se num conjunto de generalizantes singulares de cada setor, com o tempo sucessivo cronológico orientando parte por parte para uma noção do conjunto de setores visitados. O enunciado pelo papel da linguagem verbal é utilizado como legenda para essa possibilidade de generalização. "Tanque d'água" que, junto com a imagem, designam separação (a imagem é decisiva para a compreensão); "floculação", que, junto com o desenho, designam processos de concentração da poluição (também, neste caso, a imagem é determinante para a compreensão); "bomba", desenho do filtro com os escritos "areia, carvão e sal” etc. No entanto, os enunciados tiveram mais o papel de indicar e de caracterizar diferenças entre os tanques do que de generalização, ou seja, aqui eles são utilizados muito mais como indicativos de singularidades. Esse é outro exemplo de modificação do uso que foi invertido, já que, usualmente, os enunciados são sempre mais generalizantes e as imagens mais indicadoras de singularidades.

\section{Breve discussão}

Com o apoio de Martínez García (2004), posso dizer que, em cada quadrinho, predomina a forma/espaço e, na sequência dos quadrinhos, a narrativa e o tempo. É a função simbólica que, em cada momento de uma representação, decide o que é espaço ou forma, ou seja, o que é contexto e o que é objeto. Espaço e objeto são diferentes mas interdependentes 
na compreensão da significação da representação. Se os desenhos são mais complexos, com o espaço tornando-se mais contextual, a representação elaborada adquire uma narratividade. É o que acontece com a Figura 4. Cada quadrinho representa objetos, formas fechadas em si com significados (por exemplo, bomba) e, também, a relação forma e fundo (Gestalt) nos orienta para a compreensão do continente em que a forma se encontra; por outro lado, a sequência de todos esses objetos com seus sentidos cria, em nós, a noção espacial ou contexto de cada uma dessas partes no conjunto simbólico do tratamento de água.

Há vários modos de se elaborar um espaço contextual com uma maior complexidade que conjuga o próprio espaço com o tempo e, assim, adquirindo uma narratividade. Na Figura 3, a narratividade adquire a noção de ciclo com o uso das flechas. A Figura 4 é uma narrativa na forma de história em quadrinhos; a temporalidade conjugada à espacialidade de cada parte significativa para o aluno foi o eixo do contexto específico narrativo. Na Figura 3, a significação não pode prescindir das relações de referencialidade espacial e, por tratar-se de processo (tratamento de água), da referencialidade temporal. O seu papel de generalização, ou seja, capacidade de maior descontextualização, não acontece distanciando-se dos referenciais espaciais e temporais do contexto de origem da significação. Por exemplo, sem o desenho do perfil de tratamento, que busca se aproximar figurativamente do original, a compreensão do tratamento de água seria incompreensível. Os desenhos ora são mais generalizantes e é a escrita que especifica, ora são mais singulares, sem a escrita ou com a escrita generalizando. Essa complexidade de usos de formas/objetos integra-se com o espaço, e estes constituem o contexto espaço-temporal. No uso das imagens, estamos constatando que os enunciados, quando utilizados, têm o seu uso para singularizar, e não generalizar, o que inverte seu uso mais corriqueiro. A linguagem visual foi decisiva para uma maior e complexa significação dos diferentes pontos vistos na visita de campo na SANASA.

Minha hipótese é a de que o roteiro de campo e atividades decorrentes aguçaram o pensamento visual para perceber os elementos essenciais, os traços, as formas mais representativas de um campo visual (Gestalt) (ARNHEIM, 1980, 1987), que geram representações como as das Figuras 3 e 4, onde o autor (aluno), sem perder a síntese do local visitado, conjuga, articula objetos e contextos narrativos que nos informam sobre o tratamento de água. Nesse caso, a possibilidade de maior abstração e generalização não se dá pela descontextualização e distanciamento dos referentes espaço-temporais, como usualmente acontece nas generalizações verbais. As duas figuras são um bom exemplo do uso combinado contextualizado e descontextualizado das imagens e escritas.

\section{Considerações finais}

Ao longo do artigo e em cada experiência apresentada e discutida, vim fazendo diferentes breves discussões, apontando os principais pontos, em cada experiência, relacionados à minha meta de estar discutindo um modo de pensar histórico do efeito para a causa. Mais do que um modo de pensar, é uma postura diante do mundo. Postura mais observativo-interpretativa que consiga, diante de um problema, desenvolver um olhar mais indiciário-qualitativo, partindo de certas totalidades e questões instigadoras que orientem a análise, necessariamente, 
Compiani, M.

mais racional e detalhada. Nas três experiências o olhar e observação foram focados em alguma totalidade para ser compreendida, quais sejam: estática (experiência 1), um problema real (2), e contar a completa estória de uma visita de campo (3).

Uma das ideias é ir aprendendo a lidar com esse mundo visual cada vez mais infestado de milhões de informações simultâneas. As experiências parecem simples e, aparentemente, estariam distantes da minha intenção de desenvolver um modo mais histórico e argumentativo de estar no mundo, inclusive no mundo digital, porém acredito que, nas breves discussões, pude mostrar a riqueza de cada experiência. Finalizando este artigo, acrescento mais algumas ideias, a seguir.

De um modo geral, em nossas escolas, não é comum professores de Português e Artes envolverem-se em ensinar conhecimentos mais científicos, com trabalhos de campo e com outra disciplina a um nível que mostrei de interdisciplinaridade. Normalmente, as relações são multidisciplinares, cabendo à disciplina de Português, orientações para os relatórios e textos em outras disciplinas. Na segunda experiência, Português contribuiu para envolver o aluno, por meio de diferentes textos, linguagens e vocabulários, numa percepção mais aguçada da região em que vive, no sentido de qualificar o lugar da escola e onde vivem os alunos. E como foi mostrado, os gêneros linguísticos trabalhados em Português foram de fundamental importância para as explicações geográficas elaboradas pelos alunos, que o trabalho interdisciplinar demandou. $\mathrm{O}$ mesmo ocorreu com a primeira experiência na qual a disciplina de Português desenvolveu a descrição e a narração de uma paisagem geográfica.

$\mathrm{Na}$ terceira experiência, que é mais recente, começamos a desenvolver o que seriam as abstrações visuais, uma vez que, de alguma forma, conhecemos um pouco mais o que seriam as abstrações verbais. Por esse motivo, a disciplina de Artes e, também, a de Matemática foram envolvidas no projeto. Para um modo de pensar mais histórico-argumentativo, a linguagem visual conjugada com a verbal é fundamental. Não é tarefa simples trabalhar de modo interdisciplinar e introduzir atividades com desenhos, buscando o discernimento de formas, objetos, contextos que são tão relevantes para a elaboração de padrões visoespaciais de um fenômeno, uma vez que nossa escola é marcadamente verbal. As abstrações visuais que esses estudantes fizeram são diferentes das abstrações verbais. Neste artigo não há espaço para aprofundar essa discussão. O fato de conjugar espaço e tempo, formas e objetos, diferentes perspectivas e diferentes escalas traz uma complexidade de abstrações muito diferente da abstração verbal.

Voltar-se para o cotidiano dos alunos e, mesmo, dos professores que vivem nas comunidades ao redor das escolas, voltar-se para a espacialidade e temporalidade do contexto real, pressupõem relações histórico-argumentativas com esse contexto, com a situação social e com os interlocutores, alunos, professores e membros de comunidades (escolar, bairro etc.), bem como com os processos de elaborações de conhecimentos que são contínuos e descontínuos entre contextualização e descontextualização, síntese e análise rumo às elaborações mais generalizantes e histórico-espaciais tão importantes para o desenvolvimento de um pensamento, de uma pedagogia crítica que qualifique o lugar/ambiente da escola e onde vivemos. 
Narrativas e desenhos (imagens) ...

\section{Agradecimentos}

Agradeço, imensamente, às professoras Ana Mara F. Picciuto, Santa Barbosa da Silva Neta e Luzia Mara G. Teixeira, da escola Escola Estadual Dona Valentina Silva de Oliveira Figueiredo, que desenvolveram as atividades do projeto Geociências no Ensino Fundamental. Também a Magali Andrade Barbosa, Sandra R. Bianchi Sterpeloni, e Valdete Ramos de Oliveira Melo, da Escola Estadual Adalberto Nascimento, que desenvolveram as atividades do projeto Ribeirão Anhumas na Escola.

\section{Referências}

ALMEIDA, C. M. C. A representação de espaço e tempo no desenho da criança.

Pro-posições, Campinas, n. 1, p. 39-52, 1990.

ALMEIDA, M. J. de. A linguagem da nova oralidade: imagens e sons. In: FALCÃO, A. R.; BRUZZO, C. (Coord.). Coletânea lições com cinema. São Paulo: FDE, 1994. p 117-126.

ARNHEIM, R. Arte e percepção visual: uma psicologia da visão criadora. 2. ed. São Paulo: Pioneira: EDUSP, 1980.

Intuizione e intelletto. Milano: Feltrinelli, 1987.

BRUNER, J. La educación: puerta de la cultura. Madrid: Visor, 1997.

BRUNER, J.; HASTE, H. (Comp.). La elaboración del sentido: la construcción del mundo por el niño. Barcelona: Paidós, 1990.

CHAUI, M. Janela da alma, espelho do mundo. In: NOVAES, A. (Org.). O olhar. São Paulo: Companhia das Letras, 1995. p. 31-63.

COMPIANI, M. A narrativa histórica das geociências na sala de aula no ensino fundamental. In: ALMEIDA, M. J. P. M. de, SILVA, H. C. da (Org.). Linguagens, leituras e ensino da ciência. Campinas: Mercado de Letras, 1998. p. 163-182.

Reflexiones y resultados parciales del convenio de colaboración universidad/ escuela pública para la formación permanente de profesores en ejercicio con temas de geociencias. Enseñanza de las Ciencias de la Tierra, Girona, v. 7, n. 1, p. 38-46, 1999.

- ¿Las geociencias y los trabajos de campo podrán derrocar al reinado de los enunciados sobre las imágenes? Enseñanza de las Ciências de La Tierra, Girona, v. 19, n. 1, p. 26-38, 2011.

COMPIANI, M. Projeto Geociências e a formação continuada de professores em exercício no ensino fundamental: reflexões e resultados finais. Zona Próxima, Barranquilla, v. 3, p. 29-51, 2002.

COMPIANI, M. et al. Geociências e a formação continuada de professores em exercício no ensino fundamental: reflexões. Pro-posições, Campinas, v.11, n. 1, p. 25-35, 2000. 
Compiani, M.

COMPIANI et al. Sobre o Projeto Ribeirão Anhumas na Escola. In: SEMINÁRIO DO PROJETO RIBEIRÃO ANHUMAS NA ESCOLA, 6., 2010, Campinas, 2010. Anais... 1 CD-ROM.

COMPIANI, M.; PASCHOALE, C. Geologia como forma de conhecimento sintético e histórico sobre o planeta e sua adequação ao ensino de Ciências. In: SIMPOSIO SOBRE LA ENSEÑANZA DE GEOLOGÍA, 6., 1990, Tenerife. Anais... Tenerife: Universidad de la Laguna, 1990. p. 21-34.

EDWARDS, D. Em direção a uma psicologia do discurso da educação em sala de aula. In: COLL, C.; EDWARDS, D. (Org.). Ensino, aprendizagem e discurso em sala de aula. Porto Alegre: ArtMed, 1998. p. 47-74.

FRODEMAN, R. Geological reasoning: geology as an interpretive and historical science. GSA Bulletin, Boulder, v. 107, n. 8, p. 960-968, 1995.

GUIZZO, J. (Ed.) TERRA. Série Atlas Visuais. São Paulo: Ed. Ática, 1996.

HECKHAUSEN, H. Disciplina e interdisciplinaridade. In: POMBO, O.; GUIMARÃES, H. M.; LEVY, T. (Orgs.) Interdisciplinaridade - Antologia. Porto: Campo das Letras, 2006, p. $79-89$.

JAMESON, F. Espaço e imagem. 4. ed. Rio de Janeiro: Ed. UFRJ, 2006.

LEVESON, D. J. The geologist's vision. Journal of Geological Education, Bellingham, v. 36, p. 306-309, 1988.

MARTÍNEZ GARCÍA, L. M. Arte y símbolo en la infancia: un cambio de mirada. Barcelona: Octaedro, 2004.

MARTINS, I. et al. Explicações, representações visuais e retórica na sala de aula de ciências. In: ENCONTRO SOBRE TEORIA E PESQUISA EM ENSINO DE CIÊNCIAS, 1997, Belo Horizonte. Anais... Belo Horizonte: Ed. da UFMG, 1997. p. 129-138.

MARTINS, I.; GOUVÊA, G.; PICCININI, C. Aprendendo com imagens. Ciência e Cultura, Campinas, v. 57, n. 4, p. 38-40, 2005.

MAYER, V. J. Earth-systems science: a planetary perspective. Science Teacher, Arlington, v. 58, n. 1, p. 34-39, 1991.

MENEZES, P. A trama das imagens. São Paulo: EDUSP, 1997. (Texto \& Arte).

PASCHOALE, C. Geologia - qual geologia? In: COMPIANI, M. et al. (Org.). I Jornada sobre o ensino do conteúdo geológico nos $1^{\circ}$ e $2^{\circ}$ graus. São Paulo: Sociedade Brasileira de Geologia, 1984. p. 32-33.

Geologia como semiótica da natureza. 1989. Dissertação (Mestrado em Semiótica) - Pontifícia Universidade Católica de São Paulo, São Paulo, 1989.

Dupin geólogo?: uma abordagem semiótica para a geologia e o conto policial. In: LOPES, M.; FIGUEIRÔA, S. (Org.). O conhecimento geológico na América Latina: questões de história e teoria. Campinas: Unicamp, 1990. p. 241-258. 
PICCIUTO, A. M. F.; SILVA, S. B. da. Português e o estudo do meio: uma parceria com geografia - site do Laboratório de Recursos Didáticos em Geociências do Instituto de Geociências da Unicamp. Disponível em: < http://www.ige.unicamp.br/laboratórios/lrdg/ >. Acesso em: 30 jul. 2013.

POTAPOVA, M. S. Geology as an historical science of nature. In: INTERACTION of sciences in the study of the Earth. Moscou: Progress, 1968. p. 117-126.

SANTAELLA, M. L. Produção de linguagem e ideologia. 2. ed. São Paulo: Cortez, 1996.

O que é semiótica. São Paulo: Ed. Brasiliense, 1983.

SCOTT, J. (Ed.). Language and science links: classroom implications. Carlton South: Australian Reading Association, 1992.

SROUR, R. H. Modo de produção: elementos da problemática. Rio de Janeiro: Graal, 1978.

TEIXEIRA, L. M. G.; COMPIANI, M.; NEWERLA, V. Observação e produção de textos a partir de imagens geocientíficas. Ciência \& Ensino, Campinas, v. 1, n. 1, p. 41-46, 2006. 